\title{
3D FEA of cemented glass fiber and cast posts with various dental cements in a maxillary central incisor
}

\author{
Ahmed A. Madfa ${ }^{*}$, Mohsen A. Al-Hamzi ${ }^{1}$, Fadhel A. Al-Sanabani ${ }^{1}$, Nasr H. Al-Qudaimi ${ }^{2}$ and Xiao-Guang Yue ${ }^{3}$
}

\begin{abstract}
This study aimed to analyse and compare the stability of two dental posts cemented with four different luting agents by examining their shear stress transfer through the FEM. Eight three-dimensional finite element models of a maxillary central incisor restored with glass fiber and $\mathrm{Ni}-\mathrm{Cr}$ alloy cast dental posts. Each dental post was luted with zinc phosphate, Panavia resin, super bond C\&B resin and glass ionomer materials. Finite element models were constructed and oblique loading of $100 \mathrm{~N}$ was applied. The distribution of shear stress was investigated at posts and cement/dentine interfaces using ABAQUS/CAE software. The peak shear stress for glass fiber post models minimized approximately three to four times of those for $\mathrm{Ni}-\mathrm{Cr}$ alloy cast post models. There was negligible difference in peak of shear stress when various cements were compared, irrespective of post materials. The shear stress had same trend for all cement materials. This study found that the glass fiber dental post reduced the shear stress concentration at interfacial of post and cement/dentine compared to $\mathrm{Ni}-\mathrm{Cr}$ alloy cast dental post.
\end{abstract}

Keywords: Finite element method, Biomechanics, Dental post, Dental cement, Shear stress

\section{Background}

Restoration of endodontically treated tooth has been greatly enhanced by many developments in materials and techniques. In many cases, the dental post is often used after root canal treatment to restore a damaged tooth with extensive loss of coronal tooth structure specifically when $50 \%$ or massive of coronal structure have been lost (Kimmel 2000; Ferrari et al. 2001). However, the restoration of endodontically treated tooth, that including dental post, is affected by a higher risk of biomechanical failure than vital tooth (Hatzikyriakos et al. 1992). This is attributable to the relatively high fracture incidence in pulpless tooth (Salis et al. 1987) and the dental post may be displaced during function (Sorensen and Martinoff 1984). Therefore, the dental post should have enough strength to avoid fracture incidence in the remaining tooth structure and it should be cemented with sufficient bonding

\footnotetext{
*Correspondence: ahmed_um_2011@yahoo.com

${ }^{1}$ Department of Conservative Dentistry, Faculty of Dentistry, University of Thamar, Dhamar, Yemen

Full list of author information is available at the end of the article
}

strength agent to prevent the dislodgment of the dental post during function (Bouillaguet et al. 2003).

Over the past years, post materials and designs have been expanded considerably to rehabilitate the endodontically treated teeth (Ferrari et al. 2000; Brown and Hicks 2002; Schwartz and Robbins 2004). In endodontics, two types of post systems, cast metal dental and prefabricated dental posts, are usually adopted to restore a root canal and provide retention for crown. Although traditional metallic cast post can be performed treatment in one dental visit, they are gradually being replaced by prefabricated posts, particularly those made with glass fiber materials (Bitter and Kielbassa 2007). The benefits for using the glass fiber dental post are aesthetics, better biocompatibility and corrosion resistance (Boschian Pest et al. 2002; Maccari et al. 2003).

Cementation of the dental post into the root canal is critical, because the process should accomplish a seal along the root canal. An ideal luting agent must meet the basic mechanical, biological and handling requisites, such as compatibility to the tooth and tissue, non-toxic, adequate working time, sufficient bonding strength, enough

\section{楚 Springer}

(c) 2015 Madfa et al. This article is distributed under the terms of the Creative Commons Attribution 4.0 International License (http://creativecommons.org/licenses/by/4.0/), which permits unrestricted use, distribution, and reproduction in any medium, provided you give appropriate credit to the original author(s) and the source, provide a link to the Creative Commons license, and indicate if changes were made. 
compressive strength, flowability, minimal microleakage, adhesiveness, ease of excess removal, low solubility in oral fluids, esthetics, and low cost (Hill 2007). However, no luting agents have all ideal properties (Creugers et al. 1994). Additionally, many studies showed conflicting in the outcomes of tensile bond strength (Creugers et al. 1994; Mendoza and Eakle 1994; Mitchell 2000). For that reason, there is no consensus in the literature as to the superiority of any cement compared to others.

Zinc phosphate cement is still the luting agent of choice for most conventional dental post restoration, because of its easy handling characteristics and long-term clinical documentation. Recently, resin-based cements were introduced and they showed good adherence to tooth structure. Many studies reported that the resin-based cements showed significantly higher retention and resistance to fatigue compared to zinc phosphate and resinmodified glass ionomer cements (Creugers et al. 1994; Mendoza and Eakle 1994; Mitchell 2000).

As the mechanical properties of the natural teeth differ from materials restoration, the interface between the components represents the critical area for stress concentration. Determination of the stress distributions in endodontically treated tooth restored with dental post is challenged owing to small dimension and complex structure of the post. However, the investigation the stress distribution in the restored endodontically treated tooth with dental post has remained controversial issue (Asmussen et al. 2005; Santos et al. 2009).

Finite element method (FEM) has been used by several studies for attempting to know the process of stress dissipation in teeth restored by various restorations (Pegoretti et al. 2002; Boschian Pest et al. 2006; Abu Kasim et al. 2011; Madfa et al. 2014). Therefore, this study aimed to analyze and compare the stability of two dental post materials $(\mathrm{Ni}-\mathrm{Cr}$ alloy cast and glass fiber) cemented with four different luting materials (zinc phosphate, Panavia $^{\mathrm{TM}}$ resin, superbond, $\mathrm{C} \& \mathrm{~B}$ resin and glass ionomer) by investigating their shear stress transfer through the FEM (Fig. 1).

\section{Results}

Shear stress for different post and cement materials following oblique loading are presented in Figs. 2, 3 and 4. Generally, maximum shear stress concentrated at the coronal third of the root (dentine) both on the labial and palatal aspect of the root and also concentrated at apical third of post and cement/dentine interfaces, regardless of post and cement materials.

It was observed that glass fiber dental post introduced lower shear stress compared to $\mathrm{Ni}-\mathrm{Cr}$ alloy cast post as shown in Table 1. Glass fiber post dissipated interface stress excellently from the coronal to the apical parts of

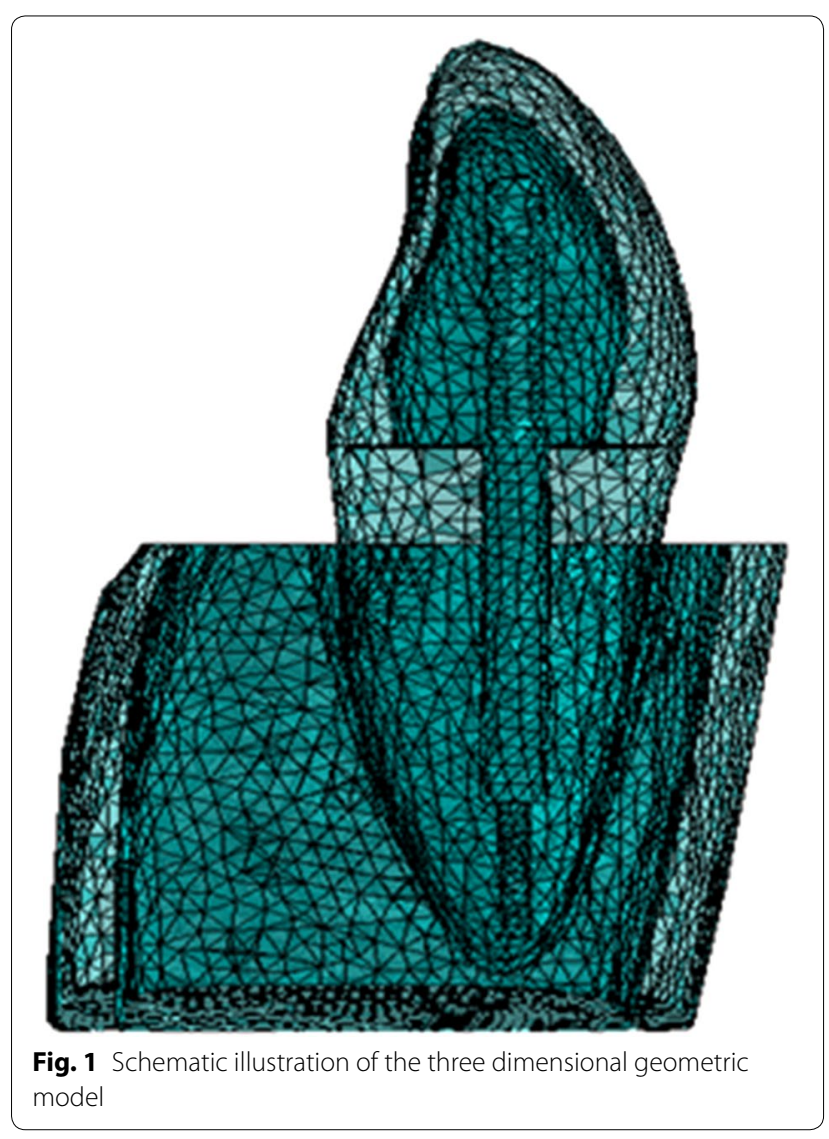

the post and dentine interface. In glass fiber models, the shear stress was considerably diminished in all regions of the interface compared to $\mathrm{Ni}-\mathrm{Cr}$ alloy cast models.

The shear stress generated in endodontically restored tooth with glass fiber post was reduced approximately three to four times of those for $\mathrm{Ni}-\mathrm{Cr}$ alloy cast post, when cement materials was disregarded. The maximum shear stress introduced by glass fiber post was $0.98 \mathrm{MPa}$ $(\mathrm{XY}), 2 \mathrm{MPa}(\mathrm{XZ})$ and $3 \mathrm{MPa}(\mathrm{ZY})$. However, the maximum shear stress for $\mathrm{Ni}-\mathrm{Cr}$ alloy cast post were 4.5 $\mathrm{MPa}(\mathrm{XY}), 6 \mathrm{MPa}(\mathrm{XZ})$ and $12 \mathrm{MPa}(\mathrm{ZY})$. There was negligible difference in the peak of shear stresses when various cements were compared, irrespective of post materials. When post materials were disregarded, the shear stress had same trend for all cement materials.

Two sites of severe interfacial shear stress concentrations were identified. The shear stress was concentrated at the interface of coronal region of root (dentine) and dental post and at the interface of apical region of root (dentine) and post (Figs. 5, 6, 7). This indicates that the interfacial failure initiation should be expected to start from the coronal and the apical regions of the dental post. The transition between positive and negative interfacial stress occurred at middle region of the root where 

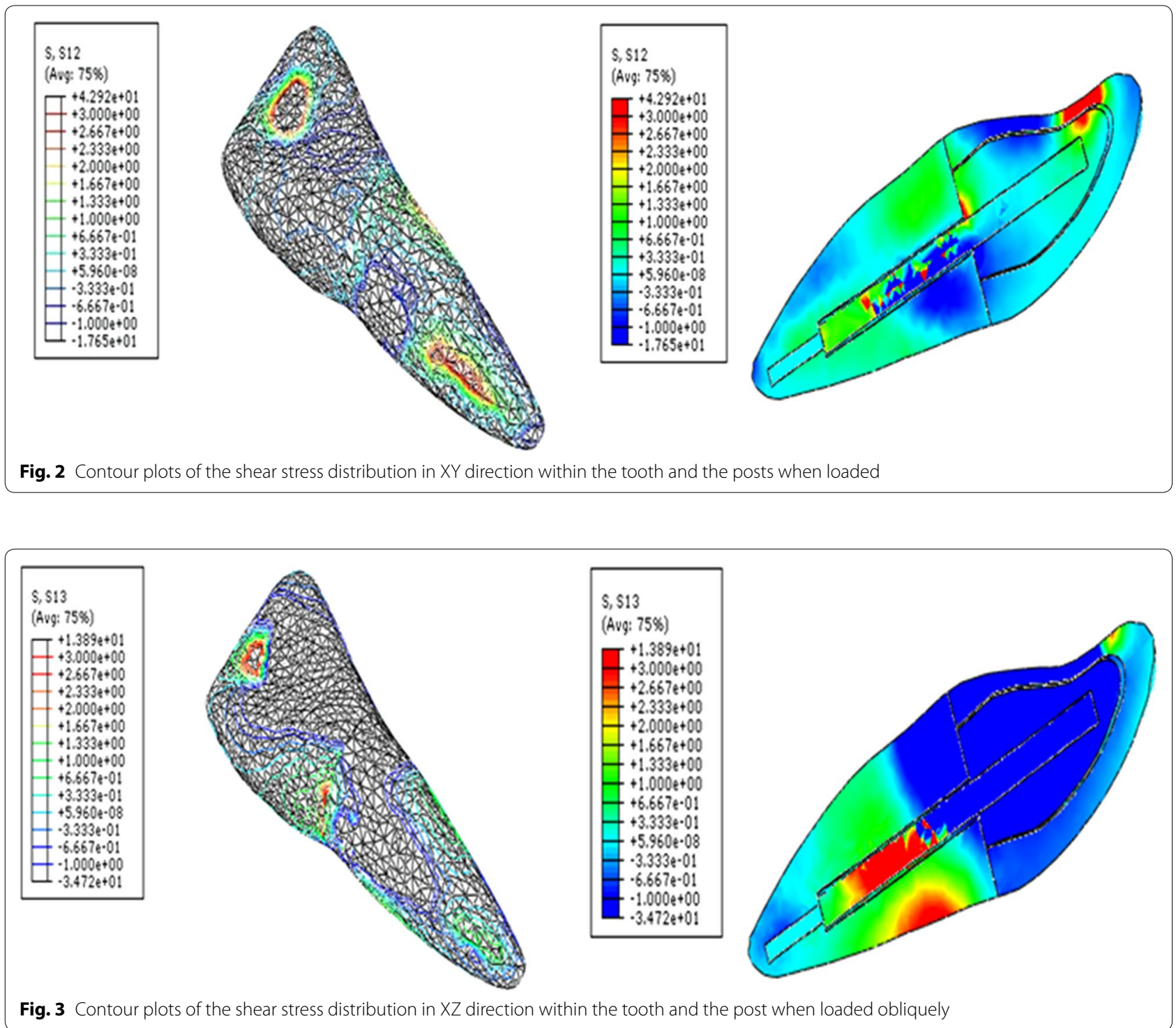

the value of interfacial stress reached zero. Similar trends were obtained among different dental cements as exhibited in Figs. 5, 6 and 7.

\section{Discussion}

The loss of retention for dental posts or root fracture is considered the main reason for biomechanical failure of the restoration (Bergman et al. 1989; Hatzikyriakos et al. 1992; Torbjorner et al. 1995). This study investigated the shear stress transfer at post and dentine/cement interface through the FEM. Calculated shear stresses may be compared to values of adherence obtained with resin based materials (Asmussen and Peutzfeldt 2001) or zinc phosphate cement to assess the risk of loss of retention of the dental post (Drummond et al. 1999). The higher interfacial stress concentration indicates interfacial failure of the restoration (Beer and Johnston 1993). Thus, in the present study, the shear stress was analyzed at three different plans to determine any sign, any pattern, and any location for the maximum values. The stresses analyzed under $\mathrm{XY}$ and $\mathrm{XZ}$ directions indicated that possibility of displacement of the dental post under the torsion and compression. Therefore, the use of adhesive cementation can contribute to minimize the risk of such displacement. However, stress analysis under ZY direction result in rupture of adhesive cementation at the tooth-post interface and it can therefore lead to loss of retention of the dental post. Thus, in order to increase the clinical lifespan of the restoration inside oral cavity, it is important to reduce stresses in the tooth and the post interface. 


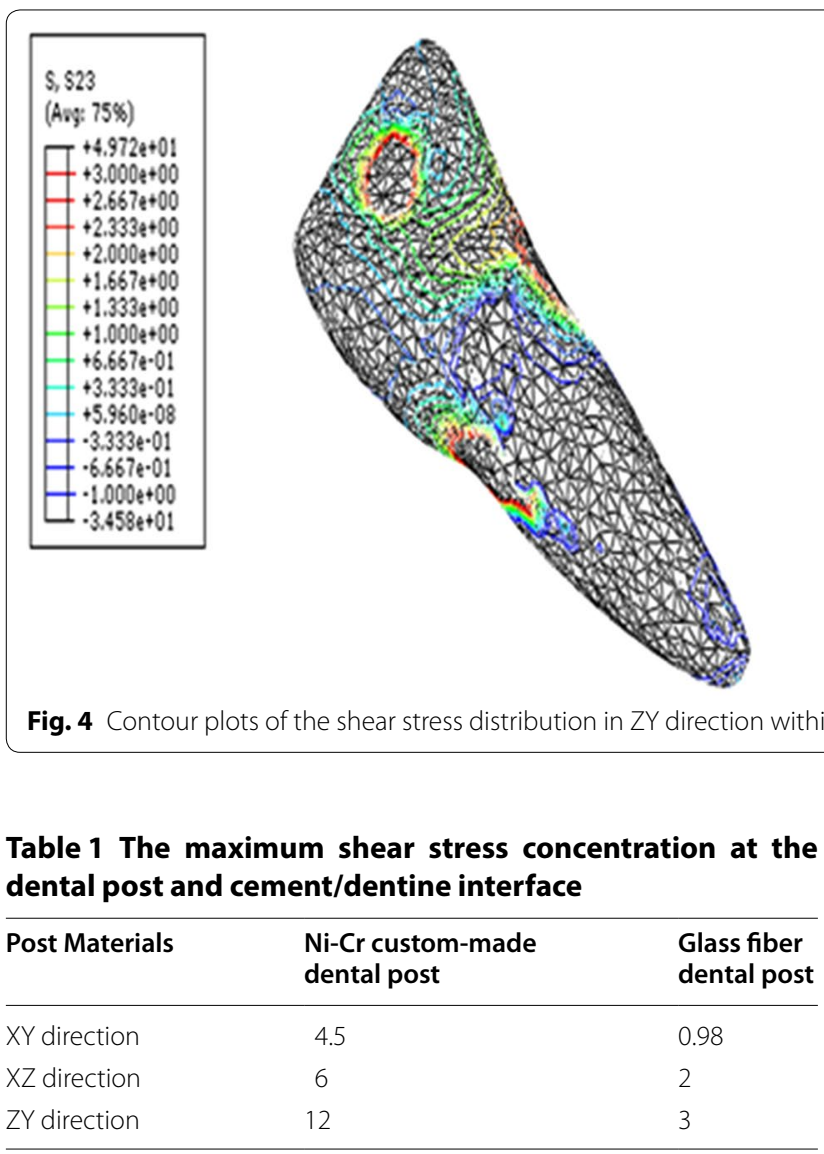

Holderegger et al. (2008) and Van Meerbeek et al. (2010) determined the bond strength of dental cements and frequently used to predict clinical behaviour of dental restorations. They reported that most annual failure rates of restorations clinically were highly correlated with the amount of shear bond strength. However, the reported bond strength values showed highly different due to the using various testing methodologies (Van Noort et al. 1989; Placido et al. 2007; Scherer et al. 2010). Additionally, the difficulty in preparing the specimens which, in turn, lead to generate non-uniform stresses within the specimens and then effect significantly on the mode of failure (Scherer et al. 2010).

To overcome these problems, FEM was used to study the shear stress distribution at the dental post and cement/dentine interface. However, accuracy and validity remain substantial challenges. In this study, accuracy was confirmed by a convergence test in which subsequent refinements of the mesh were made (Abu Kasim et al. 2011; Madfa et al. 2014). The second problem, validity, is dependent upon the extent to which the tooth model reflected the real conditions. Therefore, the models used in this study were created from a computed tomography (CT)-scan image of an adult maxillary central incisor and
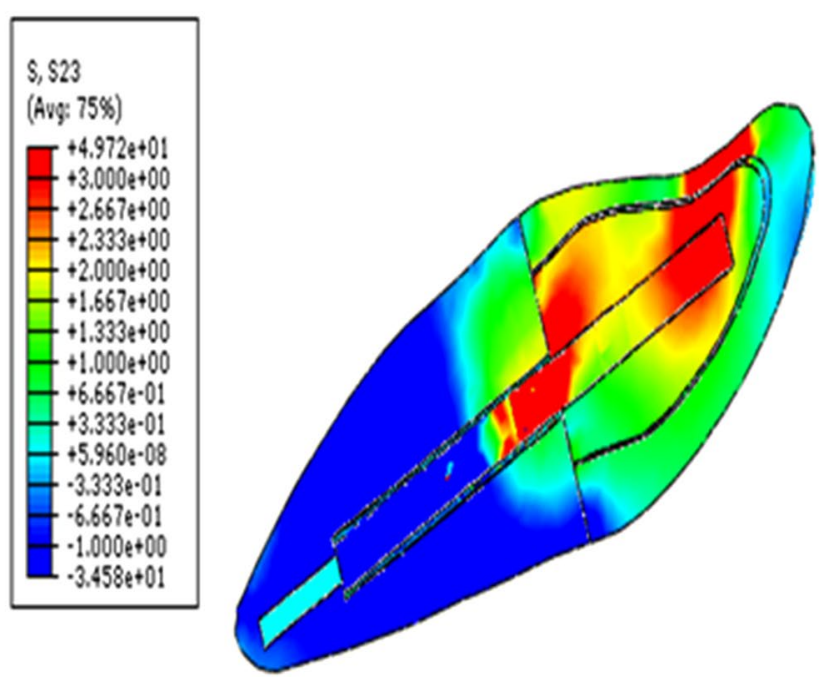

the tooth and the post when loaded obliquely

its surrounding structures. This provided a realistic rendition of clinical conditions. The oblique force of $100 \mathrm{~N}$ was obtained from the literature evaluating the mechanical behaviour of posts and cores through the FEM (Joshi et al. 2001; Asmussen et al. 2005; Al-Omiri et al. 2011; Madfa et al. 2014).

The primary role of teeth in the oral cavity is to serve as a mechanical device for the mastication of food. The stress distribution pattern in intact natural tooth is different from tooth restored with dental post system. Intact natural tooth can flex or bend during functional load while the tooth restored with dental post system showed occurrence of regions of shear stress concentration at the post and cement/dentine interfaces. This is attributable to that the post system bends or flexes as a single unit during mastication, differences of biomechanical behaviour between remaining reduced tooth structure and dental post system (Eliasson et al. 1995). Additionally, the defective in post and cement/dentine interface could cause shear stress concentration (Pegoretti et al. 2002). The results of this study were in agreement with previous studies that reported that the stress distribution were no uniform and concentrated at post and cement/ dentine interfaces (Holmes et al. 1996; Alessandro et al. 2005). They reported that a very stiff post works against the natural function of the tooth creating zones of tension and shear both in the dentine and at the interfaces of the luting cement and the post.

Asmussen and Peutzfeldt (2001) reported that bonding strength of dentine bonding systems was in the range of 15-30 $\mathrm{MPa}$, and posts luted with zinc phosphate cement can be displaced from its place during mastication at a stress level of approximately 5-25 $\mathrm{MPa}$. In this study, 


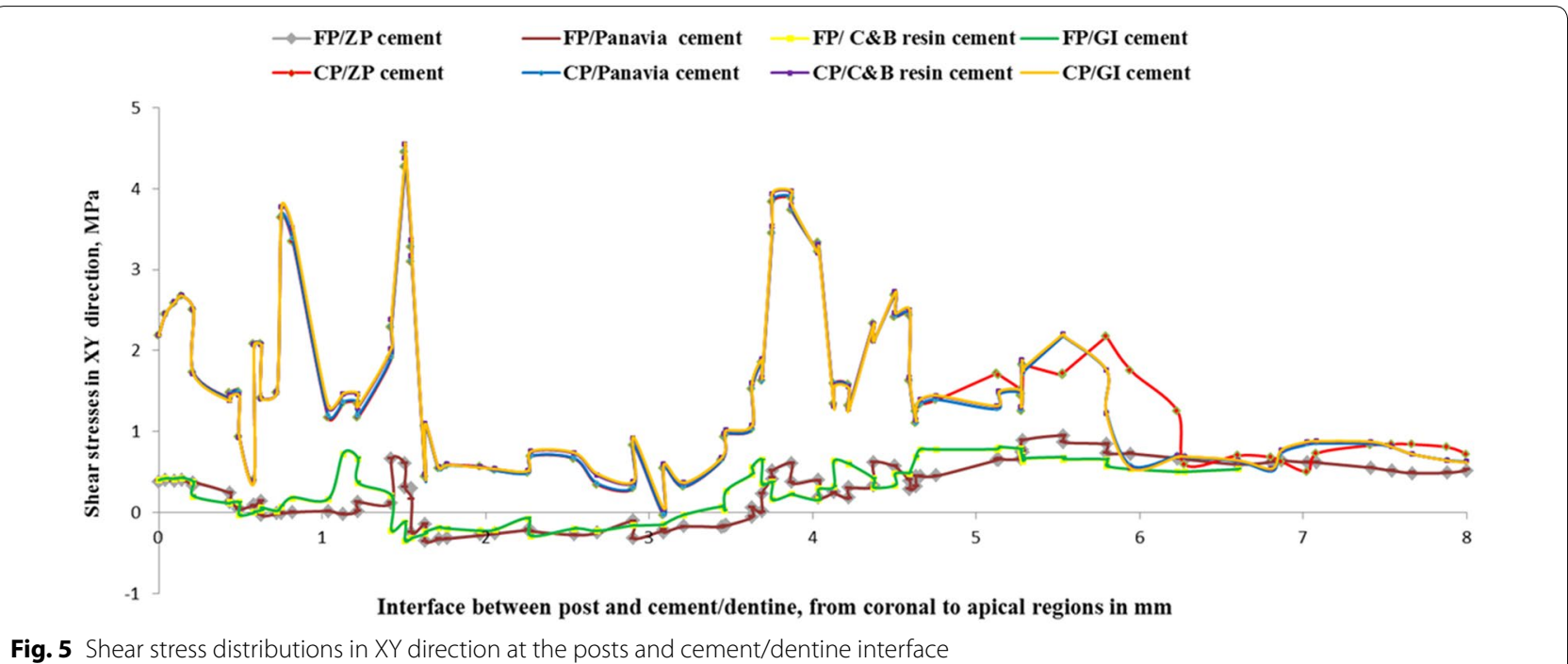

Fig. 5 Shear stress distributions in XY direction at the posts and cement/dentine interface

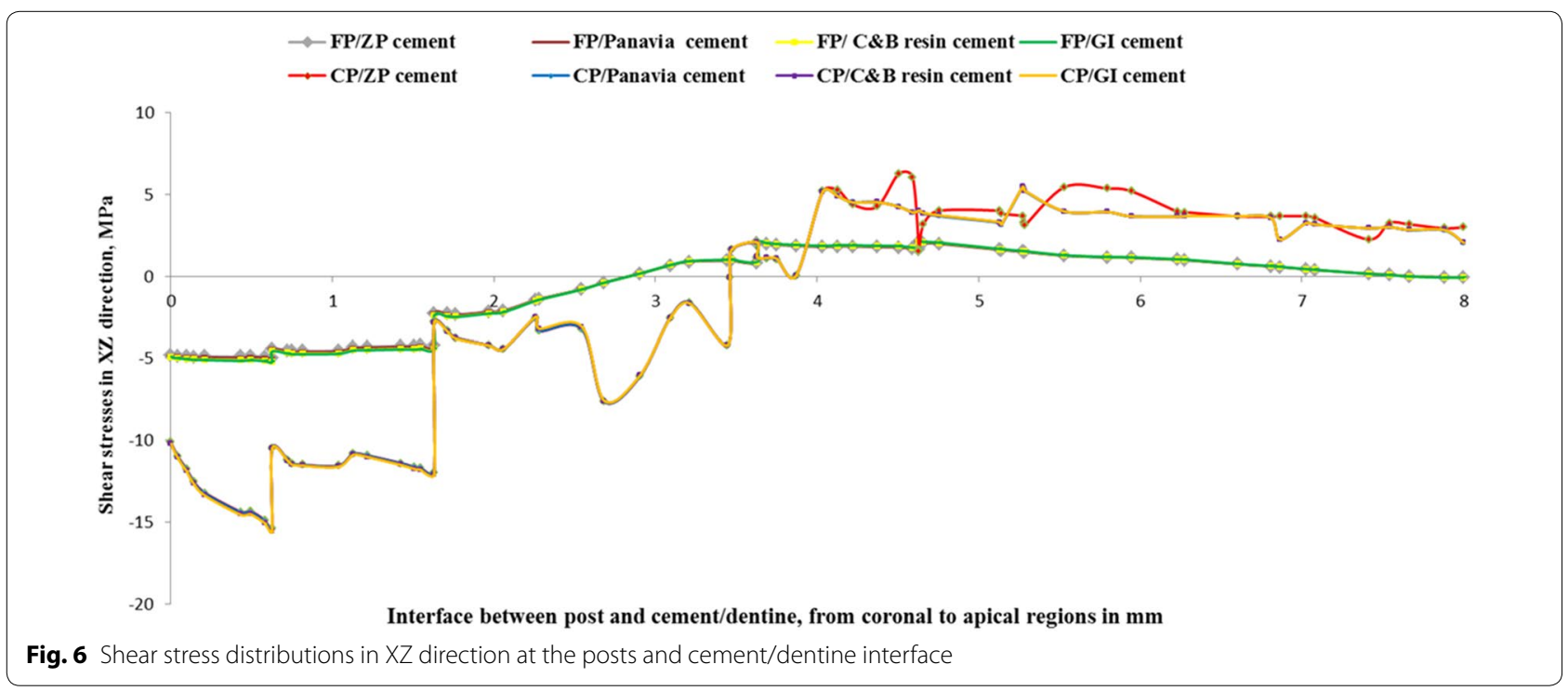

the maximum shear stresses were found to be primarily located at the post and surrounding structures interface. The maximum shear stress for the fiber post models was $0.98 \mathrm{MPa}(\mathrm{XY}), 2 \mathrm{MPa}(\mathrm{XZ})$ and $3 \mathrm{MPa}(\mathrm{ZY})$. However, the maximum shear stresses for $\mathrm{Ni}-\mathrm{Cr}$ alloy cast post models were $4.5 \mathrm{MPa}(\mathrm{XY}), 6 \mathrm{MPa}(\mathrm{XZ})$ and $12 \mathrm{MPa}$ $(\mathrm{ZY})$. There was negligible difference in the peak of shear stresses when various cements were compared, irrespective of post materials. This is attributable to that the stiffness of the dental cements used in this study was near to stiffness of dentine or less.

In the current study, the $\mathrm{Ni}-\mathrm{Cr}$ alloy cast post introduced higher shear stress than glass fiber post. This is due to the contact conditions and difference between the stiffness of the post, which cause amplification of stress magnitudes. These variable stress patterns suggest that increasing the modulus elasticity would increase the interfacial shear stress between the post and cement/dentine interface. The reduction in the interfacial shear stress diminishes the probability of post loosening from dentine as the stress on bonding cement is reduced. Therefore, this study recommended for practitioners utilizing glass fiber post to restore endodontically treated tooth. This is due to that the glass fiber post system can dissipate the interfacial shear stress remarkably from the coronal to the apical regions of the post. 


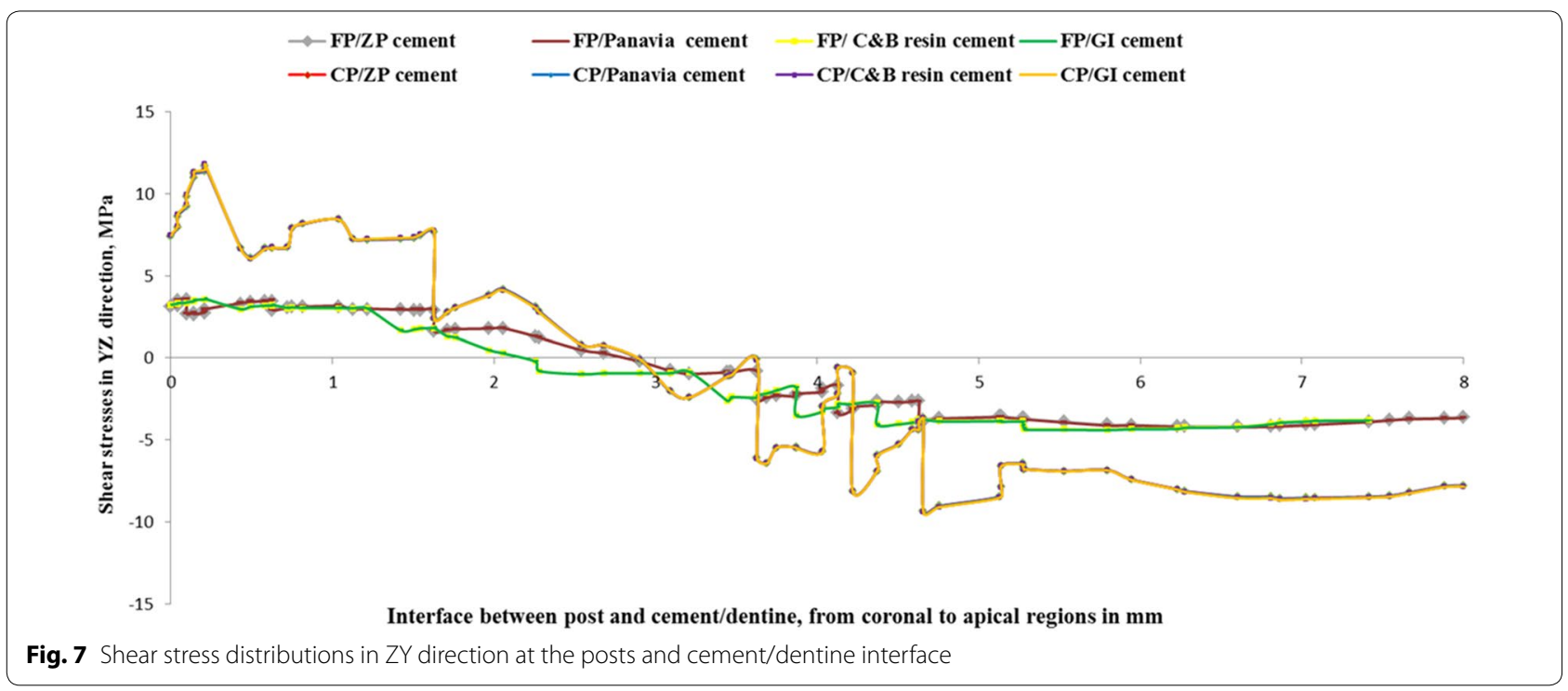

\section{Conclusions}

Glass fiber post reduced the shear stress concentration at post and cement/dentine interfaces compared to $\mathrm{Ni}-\mathrm{Cr}$ alloy cast post. The reduction in the interfacial shear stress for glass fiber post is advantageous as it likely to be able to resist cyclic loading and reduce the probability of root failure. Therefore, the chosen post with modulus elasticity near to the elastic properties of dentine is preferred.

There was negligible difference in the peak of shear stress when various dental cements were investigated irrespective of the post materials used. Similar trends of shear stress distribution were obtained among tested dental cements.

\section{Methods}

\section{Solid and FE models preparation}

A three-dimensional (3D) model of an adult maxillary central incisor with its surrounding cortical and cancellous bones was developed using a computed tomography (CT) scan. The 3D model was constructed along with their surrounding cortical and cancellous bones using Mimics software (Materialise NV, Belgium) and Hounsfield's Unit. A periodontal ligament (PDL) was modelled based on the tooth root, with a thickness of $0.25 \mathrm{~mm}$ (Madfa et al. 2014), and it was subtracted from the volume of the cortical and cancellous bone. The restorative components of endodontically treated teeth were modelled based on the geometry of the root using a 'Solid Works' (Dassault Systèmes, USA). The dimension of each component was based on the data from previous studies (Pegoretti et al. 2002; Asmussen et al. 2005; Boschian Pest et al. 2006; Santos et al. 2009; Abu Kasim et al. 2011; Madfa et al. 2014).

\section{Finite element analysis}

This study used four-node first-order linear tetrahedral solid elements (C3D4). These C3D4s used fine mesh to obtain accurate results because the constant stress on the tetrahedral elements exhibited low convergence. The nodes along the bottom line of the model, referred to as alveolar bone, were fixed in all degrees of freedom (Yang et al. 2001). All components were assumed to be perfectly bonded without any gaps between the components. An oblique load of $100 \mathrm{~N}$, angled at $45^{\circ}$, to simulate the masticatory force was chosen (Madfa et al. 2014). All forces were applied on the aforementioned area as distributed pressure. Any stresses that are likely to be introduced during the endodontic treatment were neglected. The elastic properties of the geometric model parts are shown in Tables 2, 3.

Table 2 Mechanical properties of isotropic materials

\begin{tabular}{lll}
\hline Material & $\begin{array}{l}\text { Elastic modulus } \\
\text { (MPa) }\end{array}$ & $\begin{array}{l}\text { Poisson's } \\
\text { ratio }\end{array}$ \\
\hline Cortical bone & 13,700 & 0.3 \\
Cancellous bone & 1370 & 0.3 \\
Dentin & 18,600 & 0.32 \\
PDL & 0.069 & 0.45 \\
Porcelain & 69,000 & 0.28 \\
Gutta-percha & 140 & 0.45 \\
Composite resin & 12,000 & 0.33 \\
Ni-Cr alloy & 200,000 & 0.33 \\
Zinc phosphate cement & 22,400 & 0.35 \\
Glass ionomer cement & 4000 & 0.35 \\
Panavia ${ }^{\text {TM }}$ F & 18,600 & 0.28 \\
Superbond C\&B resin cement & 1800 & 0.31 \\
\hline
\end{tabular}


Table 3 Mechanical properties of orthotropic materials

\begin{tabular}{ll}
\hline Property & Glass fiber post \\
\hline Ex (MPa) & 37,000 \\
Ey (MPa) & 9500 \\
Ez (MPa) & 9500 \\
Vxy & 0.27 \\
Vxz & 0.34 \\
Vyz & 0.27 \\
Gxy & 3100 \\
Gxz & 3500 \\
Gyz & 3100 \\
\hline
\end{tabular}

Eight 3D finite element models of a maxillary central incisor restored as follows:

1. Glass fiber post cemented with zinc phosphate cement (FP/ZP cement).

2. Glass fiber post cemented with Panavia $^{\mathrm{TM}}$ resin cement (FP/Panavia ${ }^{\mathrm{TM}}$ cement).

3. Glass fiber post cemented with superbond $C \& B$ resin cement (FP/C\&B cement).

4. Glass fiber post cemented with glass ionomer cement (FP/GI cement).

5. Ni-Cr alloy cast post cemented with zinc phosphate cement (CP/ZP cement).

6. Ni-Cr alloy cast post cemented with Panavia ${ }^{\mathrm{TM}}$ resin cement (CP/Panavia ${ }^{\mathrm{TM}}$ cement).

7. $\mathrm{Ni}-\mathrm{Cr}$ alloy cast post cemented with superbond $\mathrm{C} \& \mathrm{~B}$ resin cement ( $\mathrm{CP} / \mathrm{C} \& \mathrm{~B}$ cement).

8. $\mathrm{Ni}-\mathrm{Cr}$ alloy cast post cemented with glass ionomer cement (CP/GI cement).

The distribution of shear stress was evaluated at the dental post and cement/dentine interfaces using ABAQUS/CAE software, Professional Version. The interfacial shear stress was calculated along the $A B$ path from coronal to apical regions of the dental post and cement/ dentine. Interfacial shear stress $\left(\tau_{x y}, \tau_{x z}\right.$, and $\left.\tau_{y z}\right)$ results were virtually mapped onto $\mathrm{AB}$ path at the post and cement/dentine interfaces. The computed interfacial stress $\left(\tau_{x y}, \tau_{x z}\right.$, and $\left.\tau_{y z}\right)$ results along the $A B$ path were then analyzed.

\section{Authors' contributions}

This work was carried out in collaboration between all authors. All authors read and approved the final manuscript.

\footnotetext{
Author details

${ }^{1}$ Department of Conservative Dentistry, Faculty of Dentistry, University of Thamar, Dhamar, Yemen. ${ }^{2}$ Department of Pediatric Dentistry, Preventive Dentistry and Orthodontics, Faculty of Dentistry, University of Thamar, Dhamar, Yemen. ${ }^{3}$ Department of Safety Science and Engineering, Wuhan University of Technology, Wuhan, China.
}

\section{Acknowledgements}

The authors wish to sincerely thank Mr. Azim Oshkour at Department of Biomedical Engineering, Faculty of Engineering, University of Malaya for his assisting in finite element modelling. This work is partly supported by the Self-Determined and Innovative Research Funds of Wuhan University of Technology (No. 2014-JL-007).

\section{Competing interests}

The authors declare that they have no competing interests.

Received: 11 February 2015 Accepted: 16 September 2015

Published online: 13 October 2015

\section{References}

Abu Kasim NH, Madfa AA, Hamdi M, Rahbari RG (2011) 3D-FE analysis of functionally graded structured dental posts. J Dent Mater 30:869-880

Alessandro L, Raffaella A, Sandro R, Davide A, Antonio A (2005) 3D FEA of cemented steel, glass and carbon posts in a maxillary incisor. Dent Mater 21:709-715

Al-Omiri MK, Rayyan MR, Abu-Hammad O (2011) Stress analysis of endodontically treated teeth restored with post-retained crowns: a finite element analysis study. J Am Dent Assoc 142:289-300

Asmussen E, Peutzfeldt A (2001) The influence of relative humidity on the effect of dentin bonding systems. J Adhes Dent 3:123-127

Asmussen E, Peutzfeldt A, Sahafi A (2005) Finite element analysis of stresses in endodontically treated, dowel-restored teeth. J Prosthet Dent 94:321-329

Beer FP, Johnston R (1993) Transformations of stress and strain, mechanics of materials. McGraw-Hill International Editions, Singapore

Bergman B, Lundquist P, Sjogren U, Sundquist G (1989) Restorative and endodontic results after treatment with cast posts and cores. J Prosthet Dent 61:10-15

Bitter K, Kielbassa AM (2007) Post-endodontic restorations with adhesively luted fiber-reinforced composite post systems: a review. Am J Dent 20:353-360

Boschian Pest L, Cavalli G, Bertani P, Gagliani M (2002) Adhesive post-endodontic restorations with fiber posts: push-out tests and SEM observations. Dent Mater 18:596-602

Boschian Pest L, Guidotti S, Pietrabissa R, Gagliani M (2006) Stress distribution in a post-restored tooth using the three-dimensional finite element method. J Oral Rehabil 33:690-697

Bouillaguet S, Troesch S, Wataha JC, Krejci I, Meyer JM, Pashley DH (2003) Microtensile bond strength between adhesive cements and root canal dentin. Dent Mater 19:199-205

Brown PL, Hicks NL (2003) Rehabilitation of endodontically treated teeth using the radiopaque fiber post. Compend Contin Educ Dent 24:275-278

Creugers NH, Kayser AF, van't Hof MA (1994) A meta-analysis of durability data on conventional fixed bridges. Commun Dent Oral Epidemiol 22:448-452

Drummond JL, Toepke TR, King TJ (1999) Thermal and cyclic loading of endodontic posts. Eur J Oral Sci 107:220-224

Eliasson S, Bergstrom J, Sanda A (1995) Periodontal bone loss of teeth with metal posts: a radiographic study. J Clin Periodontol 22:850-853

Ferrari M, Vichi A, Mannocci F, Mason PN (2000) Retrospective study of the clinical performance of fiber posts. Am J Dent 13:9B-13B

Ferrari M, Vichi A, Grandini S, Goracci C (2001) Efficacy of a self-curing adhesive-resin cement system on luting glass-fiber posts into root canals: a SEM investigation. Int J Prosthodont 149:543-549

Hatzikyriakos AH, Reisis Gl, Tsingos N (1992) A 3-year postoperative clinical evaluation of posts and cores beneath existing crowns. J Prosthet Dent $67: 454-458$

Hill EE (2007) Dental cements for definitive luting: a review and practical clinical considerations. Dent Clin N Am 51:643-658

Holderegger C, Sailor I, Schuhmacher C, Schafer R, Hammerle C, Fischer J (2008) Shear bond strength of resin cements to human dentin. Dent Mater 24:944-950

Holmes DC, Diaz-Arnold AM, Leary JM (1996) Influence of post dimension on stress distribution in dentin. J Prosthet Dent 75:140-147

Joshi S, Mukherjee A, Kheur M, Mehta A (2001) Mechanical performance of endodontically treated teeth. Finite Elem Anal Des 37:587-601 
Kimmel SS (2000) Restoration and reinforcement of endodontically treated teeth with a polyethylene ribbon and prefabricated fiberglass post. Gen Dent 48:700-706

Maccari PC, Conceicao EN, Nunes MF (2003) Fracture resistance of endodontically treated teeth restored with three different prefabricated esthetic posts. J Esthet Restor Dent 15:25-31

Madfa AA, Kadir MR, Kashani J, Saidin S, Sulaiman E, Marhazlindae J, Rahbari R, Abdullah BJ, Abdullah H, Abu Kasim NH (2014) Stress distributions in maxillary central incisors restored with various types of post materials and designs. Med Eng Phys 36:962-967

Mendoza DB, Eakle S (1994) Retention of posts cemented with various dentinal bonding cements. J Prosthet Dent 72:591-594

Mitchell CA (2000) Selection of materials for post cementation. Dent Update 27:350-354

Pegoretti A, Fambri L, Zappini G, Bianchetti M (2002) Finite element analysis of a glass fibre reinforced composite endodontic post. Biomaterials 23:2667-2682

Placido E, Mira JB, Lima RG, Muench A, de Souza RM, Ballester RY (2007) Shear versus micro-shear bond strength test: a finite element stress analysis. Dent Mater 23:1086-1092

Salis SG, Hood JAA, Stokes ANS, Kirk EEJ (1987) Patterns of indirect fracture in intact and restored human premolar teeth. Endod Dent Traumatol $3: 10-14$
Santos AF, Tanaka CB, Lima RG, Espósito CO, Ballester RY, Braga RR, Meira JB (2009) Vertical root fracture in upper premolars with endodontic posts: finite element analysis. J Endod 35:117-120

Scherer SS, Cesar PF, Swain MV (2010) Direct comparison of the bond strength results of the different test methods: a critical literature review. Dent Mater 26:e78-e93

Schwartz RS, Robbins JW (2004) Post placement and restoration of endodontically treated teeth: a literature review. J Endod 30:289-301

Sorensen JA, Martinoff JT (1984) Intracoronal reinforcement and coronal coverage: a study of endodontically treated teeth. J Prosthet Dent 51:780-784

Torbjorner A, Karlsson S, Odman PA (1995) Survival rate and failure characteristics for two post designs. J Prosthet Dent 73:439-444

Van Meerbeek B, Pumas M, Poitevin A, Mine A, Van Ende A, Neves A, De Munck $J(2010)$ Relationship between bond-strength tests and clinical outcomes. Dent Mater 26:e100-e121

Van Noort R, Noose S, Howard IC, Cardew G (1989) A critique of bond strength measurements. J Dent 17:61-67

Yang HS, Lang LA, Guckes AD, Felton DA (2001) The effect of thermal change on various dowel-and-core restorative materials. J Prosthet Dent $86: 74-80$

\section{Submit your manuscript to a SpringerOpen ${ }^{\odot}$ journal and benefit from:}

- Convenient online submission

- Rigorous peer review

- Immediate publication on acceptance

- Open access: articles freely available online

- High visibility within the field

- Retaining the copyright to your article

Submit your next manuscript at $\downarrow$ springeropen.com 